\title{
periferio
}

\section{AS TECNOLOGIAS DA INFORMAÇÃO E COMUNICAÇÃO (TICS) E OS DESAFIOS DA INCLUSÃO: A CRIAÇÃO DE AULAS SINALIZADAS NO CONTEXTO DO ENSINO SUPERIOR}

\author{
Isabela Martins Miranda ${ }^{1}$ \\ Universidade Federal de Viçosa \\ Victor Luiz Alves Mourão² \\ Universidade Federal de Viçosa \\ Ana Luisa Borba Gediel ${ }^{3}$ \\ Universidade Federal de Viçosa
}

\section{Resumo}

As tecnologias de Informação e Comunicação (TICs) são, atualmente, um dos maiores facilitadores na inserção de surdos nas Instituições de Ensino Superior (GEDIEL; SOARES; OLIVEIRA, 2016). Porém, construir essas tecnologias permanece um desafio enfrentado pelos profissionais envolvidos nessa tarefa. A unidade de ensino à distância de uma Instituição de Ensino Superior na Zona da Mata Mineira criou um novo conceito de aula visando a ensejar o ensino-aprendizagem de um surdo estudante de ciências exatas, denominada aula sinalizada. 0 percurso metodológico da construção dessa nova ferramenta foi através de referencial teórico, grupos de estudos e visitas técnicas. O processo de construção desse material consiste em cinco fases. Na primeira, o professor disponibiliza o roteiro e outros materiais da disciplina para a equipe. Na segunda, é construída a glosa (FERREIRA BRITO, 1995) baseada no material. Na terceira, os surdos e intérpretes revisam a glosa e oferecem soluções aos problemas identificados. Na quarta fase, a equipe produz um audioguia e inicia as gravações das aulas sinalizadas. $\mathrm{Na}$ quinta e última fase, o material é finalizado e é disponibilizado ao aluno. A construção da aula sinalizada foi um grande desafio para a metodologia de ensino para surdos, pois, como ficou evidenciado, trata-se de um método que, apesar de eficaz, mobiliza vários agentes. O desenvolvimento desses materiais, além de proporcionar ao surdo uma real aprendizagem do conteúdo, proporciona também uma maior proximidade e integração ao cotidiano universitário.

Palavras-chave: TICs; acessibilidade; ensino superior

\footnotetext{
1 Graduanda do Curso de Secretariado Executivo Trilíngue da Universidade Federal Viçosa. Desenvolve pesquisas no campo da TICs, Libras e mapeamento por redes de contato. isabelamartinsmiranda@gmail.com

2 Professor Adjunto do Departamento de Ciências Sociais da Universidade Federal de Viçosa. Doutor em sociologia pelo Instituto de Estudos Socias e Políticos (IESP-UERJ).

${ }^{3}$ Antropóloga e professora Adjunta IV do Departamento de Letras da Universidade Federal de Viçosa (UFV). Pesquisadora associada ao Grupo de Pesquisa do CNPq: Crenças sobre Ensino e Aprendizagem de Línguas (CEALI).
} 


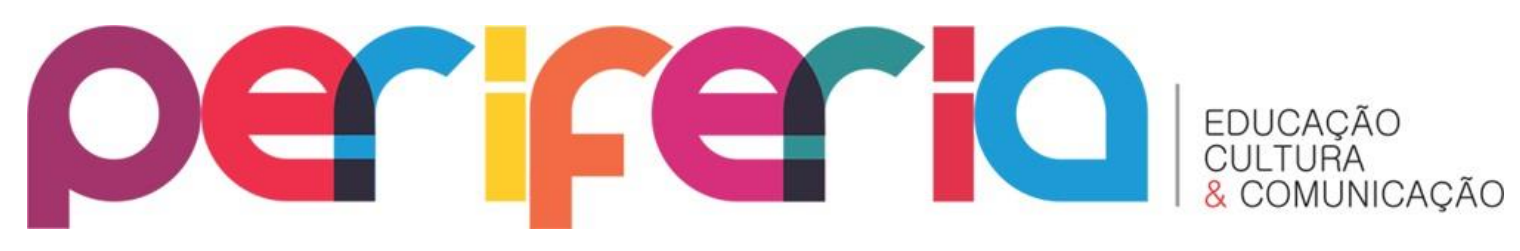

\title{
THE INFORMATION AND COMMUNICATIONS TECHNOLOGY (ICTS) AND THE INCLUSION CHALLENGES: CREATING SIGN CLASSES IN UNIVERSITIES
}

\begin{abstract}
The ICT's (Information and communications technology) are nowadays one of the most proficuous instruments in providing acessibility to deaf people in the higher education institutions (GEDIEL; SOARES; OLIVEIRA, 2016). However, develop these technologies is a challenge faced by professionals involved in that task. A university from Minas Gerais' Zona da Mata developed a new class conception based in e-learning to empower the learning/teaching process of a deaf Math sciences student from that institution: the sign class. The methodology of building this new tool was made through a theoretical reference, study groups and technical visits. The process of developing this material was made in five stages. On the first, the teacher provides the class script and other teaching instruments of the course to the team. On the second, the "glosa" (FERREIRA BRITO, 1995) is made based on the content provided. Third, the deaf people and the translators review the "glosa" and provide solutions to identified problems. Fourth, the team create a audioguide and begins to record the sign classes. Fifth and the last phase, the material is finished and made available to the student. The development of the sign class was a huge challenge to the methodology of teaching deaf people, because is all about a method that harness various people. The creation of these content, as well as provide the deaf people a real learning of the course, also provides a better proximity and integration in the university lifestyle.
\end{abstract}

Keywords: ICTs; acessibility; higher education 


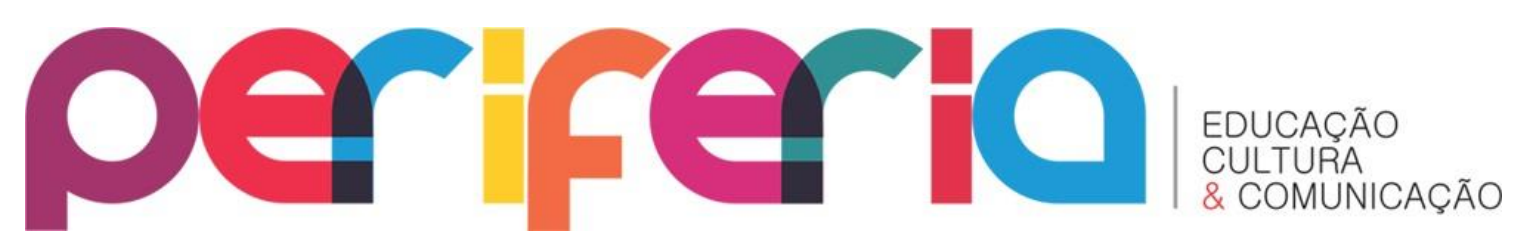

\section{INTRODUÇÃO}

As Tecnologias da Informação e Comunicação (TICs) apresentam, cada vez mais, um importante papel no ambiente educacional. Elas facilitam potencialmente o modo de interação entre o professor e aluno ao viabilizar a exploração de recursos didáticos inovadores, ao diversificar os modos de criar conhecimentos e ao possibilitar a obtenção de informações atualizadas. As TICs são consideradas como catalisadores de transformações na educação, tanto para ensinar, quanto para aprender (MOROSOV, 2008).

A mediação das TICs engloba a compreensão dos processos de gestão de tecnologias, recursos, informações e conhecimentos. Esse processo abarca relações dinâmicas e complexas de elaboração e organização, de produção e manutenção, como os núcleos de produção de materiais, seus projetos e suas relações de equipe (ALMEIDA; ALMEIDA, 2005). A utilização dessas tecnologias possibilita criar uma sala de aula mais dinâmica, democrática e atrativa.

Surgiram, nesse contexto, muitas reflexões acerca da necessidade de transformação do espaço escolar para a inclusão de todos em sala de aula. Desse modo, a legislação tem contribuído historicamente para o processo inclusivo e para a adoção de metodologias. A Declaração de Salamanca (1994), que é um marco para a educação inclusiva, foi adotada como base e apoiada via Lei de Diretrizes e Bases Nacional - LDBEN - n 93.94/96, dando início ao processo de adoção de um sistema educacional inclusivo no Brasil. Assim, as escolas deveriam passar a incluir, na sala de aula regular, todos sujeitos considerados pessoas com deficiência (BRASIL, 1996). Sendo assim, a sala de aula passou a ser mais diversa e, com isso, os professores passam a ter o desafio de adaptar seu modo de ensino tradicional para ensejar uma boa aprendizagem a todos.

Nesse contexto, estão inseridos os surdos, que possuem uma língua própria, de modalidade espaço-visual, a Libras (Língua Brasileira de Sinais), e a utilizam como principal meio de comunicação, sendo esta considerada sua primeira língua. William Stokoe (1978) salientou a importância da modalidade 


\section{periferio}

visual das línguas de sinais das seguintes maneiras: despertando a aceitação das línguas de sinais como "linguísticas"; apresentando uma nova perspectiva sobre a linguagem; e trazendo novas perspectivas para o campo sobre a linguagem humana. Portanto, os materiais e os contatos visuais são de extrema importância para a comunicação e o ensino/aprendizagem dos surdos.

Situando-nos na realidade do ensino superior, a educação de surdos integra a abordagem das TICs, já que estas permitem a interação em interface visual de forma mais ampla do que a partir de outros recursos tradicionais (GEDIEL; SOARES; OLIVEIRA, 2016). Essas tecnologias são regularmente utilizadas dentro da sala de aula, a partir do momento em que os professores as utilizam através das apresentações multimídias, da lousa digital, do data show, entre outros.

Por mais que as aulas sejam adaptadas e interativas, surge a problemática de como o estudante surdo consolidará e aperfeiçoará os conhecimentos fora da sala de aula em um contexto de educação híbrida, com um combinação do presencial com o virtual (GARRISON; VAUGHAN, 2008; SCHLÜNZER JR et al, 2016). Os materiais de apoio para estudo não são adaptados e os livros universitários disponíveis raramente possuem imagens e ilustrações, dificultando a tarefa de estudar entre as aulas e compreender o conteúdo de forma mais completa.

A partir da necessidade de tornar as disciplinas mais acessíveis para um estudante surdo da área das exatas de uma instituição de Ensino Superior da Zona da Mata Mineira, surgiu a proposta de um novo conceito na educação: a aula sinalizada. Desse modo, este artigo tem o objetivo de descrever o processo de criação da aula sinalizada, como a equipe foi criando estratégias a partir da problematização evidenciada no contexto de sala de aula e na complexidade de transmitir os conhecimentos de uma língua da modalidade oral para uma língua da modalidade espaço-visual. Para isso, são evidenciadas as propostas consideradas ao longo da criação da aula, os desafios enfrentados, a elaboração da metodologia e os resultados auferidos nesse processo. 


\section{periferio}

\section{DISCUSSÃO TEÓRICA}

A temática presente neste artigo emerge como uma importante aliada no processo de ensino/aprendizagem de uma língua que vem sendo objeto de pesquisas em diversas áreas, além de possuir respaldo legal: a Libras. Esta se organiza como uma língua natural própria da comunidade surda brasileira, sendo reconhecida juridicamente no Brasil por meio da Lei $n^{0} 10.436$, de 24 de abril de 2002 (BRASIL, 2002). A partir disso, algumas medidas foram tomadas para garantir seu uso e divulgação.

Dessa maneira, o Decreto $n^{\circ} 5.626$, de 22 de dezembro de 2005 (BRASIL, 2005), regulamenta a referida lei e institui a inclusão da Libras como disciplina curricular nos cursos de licenciatura, sendo opcional para as demais graduações. 0 decreto visa, ainda, a assegurar aos surdos medidas de acesso à educação e à saúde.

Atualmente, tendo em vista a premência do conhecimento da Libras na formação acadêmica, abre-se espaço para a formação dos futuros profissionais com domínio da língua e a entrada de pessoas surdas em intuições de nível superior.

Segundo dados do Instituto Nacional de Estudos e Pesquisas Educacionais Anísio Teixeira (INEP), entre 2000 e 2010, as matrículas de estudantes com deficiência em Instituições de Ensino Superior aumentaram em 933,6\%, tornando-se notória, então, a discussão da inclusão e adaptação desses alunos à sala de aula (MEC/INEP, 2012). Em especial, dos surdos, já que estes possuem outro código linguístico como primeira língua.

Considerando que a Libras é uma língua natural dos sujeitos surdos, ou seja, ela possui uma estrutura linguística e gramatical própria (FERREIRA BRITO, 1995). Estas são organizadas a partir de uma sintaxe particular entendida como espaço-visual (GESSER, 2009). Nesse contexto, observa-se que o imagético assume a possibilidade de mediação da compreensão de mundo, compreensão ligada diretamente à língua e à cultura das pessoas 


\section{periferio}

surdas que utilizam a LIBRAS como principal meio de comunicação.

Para percebermos a importância desse aspecto, é interessante nos reportarmos ao debate temático do reconhecimento, no qual as produções e o diálogo de Nancy Fraser e de Axel Honneth figuram como centrais (FRASER E HONNETH, 2003; HONNETH, 2003; FRASER 2006).

Os autores trabalham com a relação de dois conceitos: "redistribuição" e "reconhecimento". O primeiro aspecto ressalta os aspectos ligados à desigualdade econômica e material. A desigualdade socialmente existente poderia ser reparada através de um processo de redistribuição do capital econômico produzido socialmente. Por outro lado, o reconhecimento admite como culturalmente válida a diversidade social nas relações humanas. Há um deslocamento no modo como se compreende a igualdade: enquanto no âmbito redistributivo a igualdade seria alcançada com um processo de equalização dos recursos materiais disponíveis para os grupos sociais e cidadãos, no âmbito do reconhecimento trata-se de incluir grupos e pessoas sem solapar aspectos identitários e sem confundir diversidade cultural com desigualdade material. Ao promover a inclusão, é necessário estar atento aos tipos de problema que serão enfrentados.

Um exemplo dessa questão é a opção obrigatória de Closed Caption nas televisões. É um direito dos surdos a inserção de legendas em todos os conteúdos transmitidos pelas canais televisivos. Porém, essas legendas não tornam os programas mais acessíveis para surdos: a legenda é pouco efetiva, já que o português, não sendo a primeira língua dos surdos, não reconhece a sua especificidade cultural de possuir uma língua própria: a Libras. É habitual, além disso, nos depararmos com legendas que passam de modo rápido, inviabilizando uma compreensão adequada, principalmente $d r$ frases curtas e com metáforas. Percebe-se, então, a intenção de promover a igualdade, mas o surdo não é reconhecido como ser que possui sua própria língua. Assim, a inclusão deve acontecer nessa linha do reconhecimento da diversidade linguístico-cultural.

Para conciliar essa relação entre redistribuição e reconhecimento, 


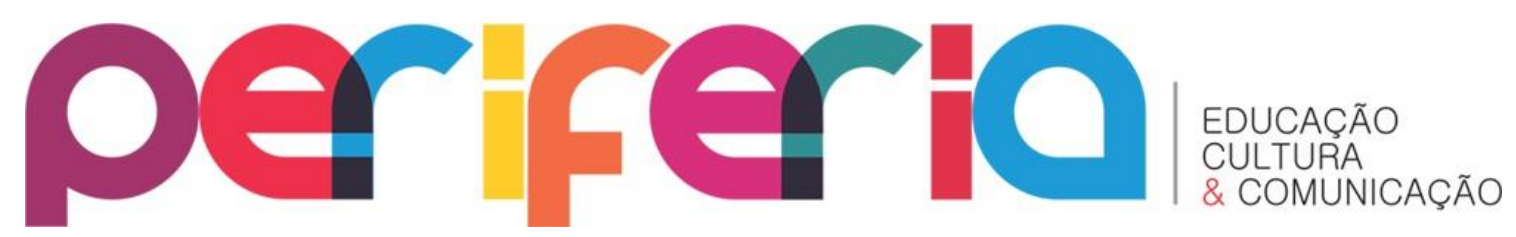

Honneth traz três esferas de reconhecimento autônomas. Uma delas é a esfera da legalidade, que seria a igualdade de condições legais entre os seres humanos. Faz-se necessário, então, proporcionar e promover condições para que essa igualdade seja estabelecida na sociedade.

As políticas sociais foram vistas principalmente a partir do prisma econômico, em que políticas redistributivas - ou seja, de promoção de um incremento na renda ou de acesso a bens e serviços públicos - tomaram preponderância em relação a políticas de reconhecimento da diversidade social, étnica e racial das populações. Assim, problemas típicos da dimensão de reconhecimento (de cunho simbólico-identitário) foram compreendidos e tratados a partir do ponto de vista da desigualdade material (de caráter econômico), confundindo fenômenos sociológicos diferentes que recebiam, portanto, soluções ineficazes e inadequadas - como se pudéssemos resolver problemas de ordem cultural-identitária nos restringindo a medidas políticas de âmbito material.

As políticas inclusivas surgem justamente para buscar meios de encontrar soluções eficazes e adequadas para a inclusão na sociedade. No âmbito da inclusão de surdos na sociedade, ela acontece quando a Libras é aceita pelos demais e passa a ser disponível, em todas as ocasiões, para seus usuários.

Assim, a criação de conteúdos didáticos acessíveis surge, no caso dos surdos, para disponibilizar materiais pedagógicos nessa língua. É importante ressaltar que essa criação não se restringe a um aspecto meramente material de acesso à educação superior, mas, especialmente, por um lado, ela é capaz de promover processos de reconhecimento da diferença surda no âmbito da sociedade brasileira e, por outro, de realizar, de maneira mais efetiva, os processos de ensino-aprendizagem através desse reconhecimento, como será exposto abaixo. 


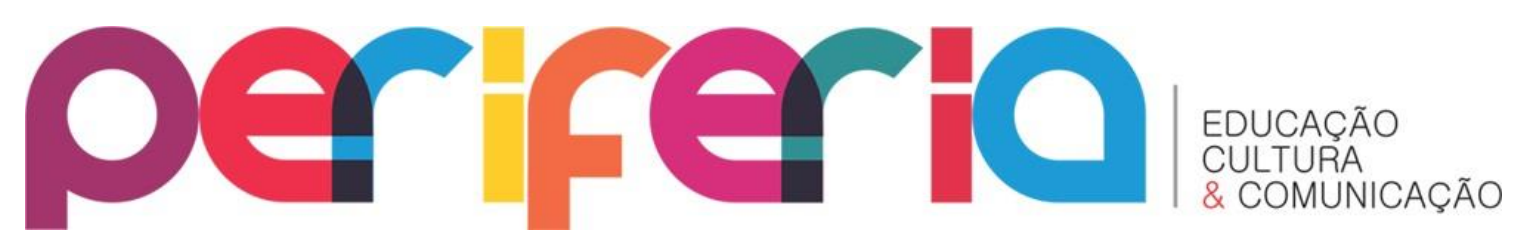

\section{PERCURSO METODOLÓGICO}

Para o desenvolvimento desta pesquisa, foi utilizado o método qualitativo. Segundo Marilu Martinelli (1999), a pesquisa qualitativa se insere no marco de referência da dialética, direcionando-se, fundamentalmente, pelos objetivos buscados. 0 desenho da pesquisa qualitativa deve oferecer uma visibilidade muito clara do objeto, do ponto de partida, do objetivo e da metodologia.

A proposta principal da pesquisa desenvolvida era mapear as TICS utilizadas para o ensino/aprendizagem da Libras na instituição abarcada. Desse modo, utilizou-se o Mapeamento de Redes de Contato (BARNES, 1987), que consiste em investigar as ligações de um determinado grupo de indivíduos, como elas se formam, descobrir quem são os envolvidos nessa rede, quem são os mais influentes, quais são os objetivos convergentes e divergentes.

Para a coleta de dados, utilizou-se entrevistas, pois, através delas, se obtêm dados subjetivos que se relacionam às atitudes e percepções do entrevistado (QUARESMA, 2005). Para o tipo de entrevista, a mais adequada foi a semiestruturada (TRIVIÑOS, 1987), que combina perguntas abertas e fechadas, possibilitando que o participante comente mais sobre o tema, além de permitir que o entrevistador faça perguntas adicionais ou se foque mais em algo que acreditou ser interessante. Todas as entrevistas foram realizadas pessoalmente. Destaco ainda que as entrevistas com os participantes surdos foram feitas em Libras, sem a mediação do intérprete.

Em relação ao Mapeamento das Redes de Contato, o ponto de entrada na rede ocorreu a partir do segundo órgão máximo da instituição, com foco em ensino. 0 representante dessa unidade informou sobre o andamento de alguns projetos na instituição voltados para a inclusão de surdos e indicou pessoas envolvidas e que poderiam ter mais conhecimento sobre o tema da pesquisa. Os indicados foram entrevistados e, por seu turno, também indicavam outros envolvidos, possibilitando a formação de uma rede de 


\section{periferio}

contatos no âmbito do campo de pesquisa.

Ao total, a rede foi composta por 15 pessoas, as quais tinham envolvimento direto ou indireto com ações voltadas para o desenvolvimento de metodologias de ensino para surdos na instituição. Foi possível observar que os entrevistados passaram a indicar pessoas já mencionadas, concluindose daí que a rede constituída por essa instituição é efetiva (BARNES, 1987), pois não possui uma grande extensão. Ou seja, redes de pequeno porte são mais flexíveis, permitem maior comunicação entre os usuários, uma comunicação com menos ruídos e com mais contribuições entre os colaboradores.

Segundo os conceitos de Barnes (1987), a rede analisada também pode ser caracterizada como fechada por haver várias repetições de estrelas (componente da rede que é frequentemente citado pelos outros componentes) e integrantes. Essa é uma característica muito presente na rede analisada, porque a maioria dos participantes é citada várias vezes por outros, tornando a rede muito sólida e concentrada em um pequeno grupo de pessoas.

Também consideramos, conforme Barnes (1987), que a nossa rede pode ser também classificada como aberta, devido à baixa intensidade de segregação dos papéis: as mesmas pessoas desenvolvem os mesmo papéis na rede durante toda a trajetória do ramo de TICs na instituição. Ainda que os projetos mudem, a diversidade de papeis exercidos pelos indivíduos permanece semelhante, assim como as funções desempenhadas por eles (BARNES, 1987).

Por fim, identificamos essa rede como limitada, já que, em função do grande poderio dos seus componentes, ela não abrange uma diversidade acentuada de indivíduos. Apesar de ser uma rede com poucos contribuintes, é uma rede interdisciplinar, pois os profissionais são de diferentes áreas do conhecimento, tanto no que se refere à formação, quanto à atuação. Portanto, as pessoas que compõem a rede pertencem a unidades $\mathrm{e}$ administrações diferentes e, consequentemente, a ações distintas. No 


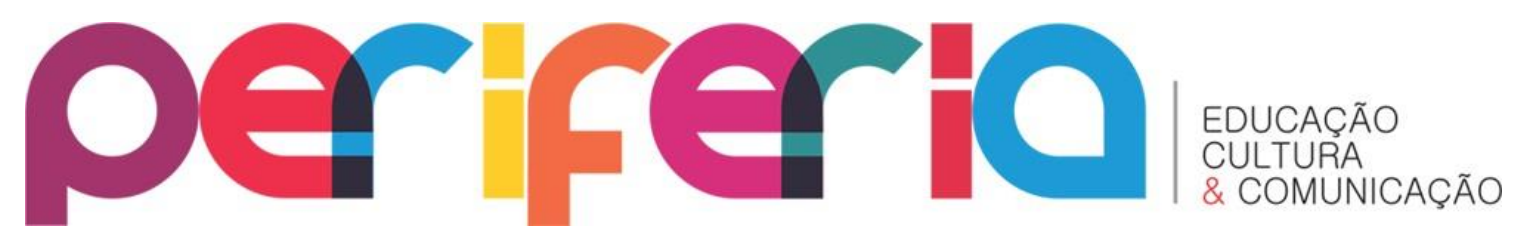

entanto, todos unem esforços para um mesmo objetivo, o de construção de TICs acessíveis e voltadas para o ensino/aprendizagem em Libras.

Para coletar os dados necessário para a pesquisa foram realizadas entrevistas ao longo do período de 2016, somando um total de 12 entrevistados. Por questões éticas, todos os entrevistados assinaram um termo de consentimento livre e esclarecido, o qual informa o sigilo da pesquisa, conforme a resolução CNS 466/2012. Todas as entrevistas foram gravadas com uma vídeo filmadora, transcritas em língua portuguesa e arquivadas. As imagens e as informações nelas contidas foram utilizadas somente para fins científicos. Foram também preservados os nomes dos entrevistados e das instituições. Para possibilitar a apresentação dos dados, os entrevistados foram classificados pela ordem cronológica de entrevista, sendo que as mulheres foram denominadas "Maria" e os homens, "João", denominações essas que foram seguidas por um segundo nome aleatório com a letra inicial em ordem alfabética. Na tabela abaixo, é possível observar essa ordem de organização dos dados, além da categorização dos elementos de acordo com a teoria de Barnes (1987). As instituições foram intituladas também em ordem alfabética por ordem de aparecimento no mapeamento.

Barnes trata como alfa os contatos mais influentes do meio, ou seja, "originador que toma a decisão de agir para atingir um objetivo específico, aquele que ativa algumas ou todas as relações sociais" (BARNES, 1964, p.167). $\mathrm{Na}$ rede, há outros tipos de usuários também, como os betas e estrelas, que são os agentes conectados a alfa e complementam a rede. "Os indivíduos que estivessem em relação direta seriam Estrelas, enquanto aqueles que não fossem diretamente ligados a Alfa, mas estivessem ligados a um agente diretamente a ela relacionado, seriam Betas" (BARNES, 1964, p.169). 


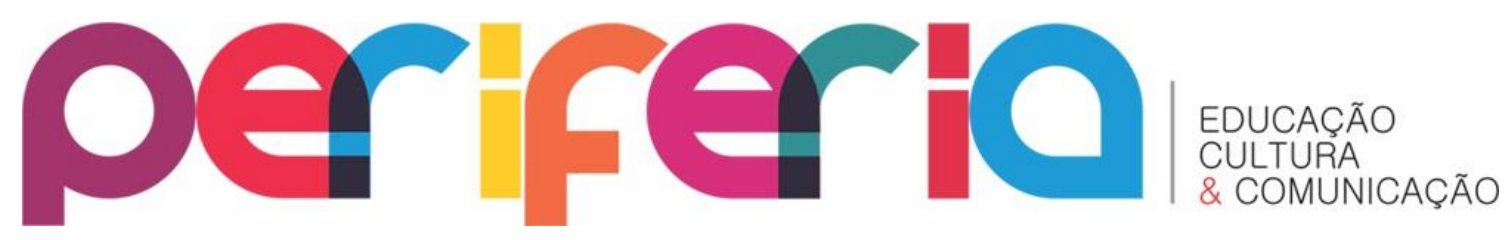

Tabela 1: Entrevistados e Classificação da posição na rede

\begin{tabular}{|l|l|l|l|}
\hline \multicolumn{1}{|c|}{ Nome } & Característica & Citações & \multicolumn{1}{c|}{ Classificação } \\
\hline João André & Ouvinte & 1 & Alfa \\
\hline João Bosco & Ouvinte & 2 & Estrela \\
\hline João Carlos & Ouvinte & 2 & Estrela \\
\hline João Daniel & Ouvinte & 4 & Estrela \\
\hline João Eduardo & Ouvinte & 3 & Estrela \\
\hline João Felipe & Surdo bilíngue & 3 & Estrela \\
\hline João Gabriel & Ouvinte & 1 & Beta \\
\hline Maria Alice & Ouvinte & 4 & Alfa \\
\hline Maria Beatriz & Ouvinte & 1 & Alfa \\
\hline Maria Carolina & Ouvinte & 1 & Beta \\
\hline Maria Dalva & Ouvinte & 2 & Estrela \\
\hline Maria Eugenia & Ouvinte & 1 & Beta \\
\hline Maria Fernanda & Ouvinte & 1 & Beta \\
\hline Estudante Surdo & Surdo bilíngue & 4 & Alfa \\
\hline Estagiários & Ouvintes & 2 & Beta \\
\hline
\end{tabular}

A partir dessas entrevistas, vários projetos foram citados, alguns mais de uma vez, como foi o caso do Projeto Um que visa a desenvolver materiais didáticos em Libras voltados para a ciências exatas.

\section{O PROCESSO DE CONSTRUÇÃO}

$\mathrm{Na}$ primeira entrevista, com o diretor da segunda maior unidade da instituição, o Projeto Um foi citado, em especial, porque na data da pesquisa este era o maior projeto envolvendo Libras e TICs em execução na instituição. Segundo o relato do entrevistado, tratava-se de um projeto desafiador e inovador: nunca havia sido feito nada parecido na instituição. Foi necessário buscar metodologias inovadoras, a aula sinalizada, e realizar estudos para construir um método próprio de resolução dos problemas técnicos e didáticos. Tratava-se de um projeto que envolvia profissionais de áreas diferentes, com conhecimentos e concepções diferentes e que, no entanto, cooperavam em busca de um método pioneiro.

O Projeto Um é de autoria da Unidade à Distância da Instituição. 0 objetivo é criar material inclusivo para educandos da instituição que possuem 


\section{periferio}

deficiência ${ }^{4}$ e, também, para estudantes de todo o Brasil. A demanda do ano de 2016 foi atender um estudante surdo de um curso das ciências exatas. Apesar da presença dos intérpretes durante as aulas, notava-se que o surdo não possuía material de apoio adaptado para estudar o conteúdo fora da sala de aula. Com isso, criou-se o projeto de formação e produção de material didático bilíngue Libras/Português para conteúdos programáticos que abarca três disciplinas do curso. Uma relacionada a transporte, outra sobre traçado geométrico em estradas e por fim, geologia.

$\mathrm{O}$ processo de construção desse material consiste em cinco fases. $\mathrm{Na}$ primeira, o professor disponibiliza o roteiro e outros materiais da disciplina para a equipe. Na segunda, é construída a glosa baseada no material. A glosa em português (FERREIRA BRITO, 1995) é o texto traduzido mais os comandos de sinalização, porque ainda que o vídeo seja em Libras, é necessário que haja um audioguia para instruir o intérprete na sinalização e também para auxiliar o editor no momento da edição do vídeo. Na terceira, os surdos e intérpretes revisam a glosa e oferecem soluções aos problemas identificados. $\mathrm{Na}$ quarta fase, a equipe produz um audioguia e inicia as gravações das aulas sinalizadas. Na quinta e última fase, o material é finalizado e é disponibilizado ao aluno.

Para cada disciplina, há um estagiário de um curso específico das ciências exatas para auxiliar na construção do material. Na equipe, também estão envolvidos os funcionários da Unidade de Ensino à Distância da Instituição, que possuem o aparato e conhecimento tecnológicos.

A demanda da construção desse material chegou à Unidade de Ensino à Distância através da Unidade Inclusiva. 0 pedido foi a legendagem do material didático produzido pelo professor da disciplina. Após algumas pesquisas, a unidade concluiu que esse tipo de moldagem não traria um benefício eficaz para o estudante, pois precisaria ser feito algo na primeira língua do aluno, a Libras. A demanda também foi trazida em 2015, porém a equipe foi

\footnotetext{
${ }^{4}$ Nomenclatura Lei de Diretrizes e Bases Nacional - LDBEN - n $93.94 / 96$
} 


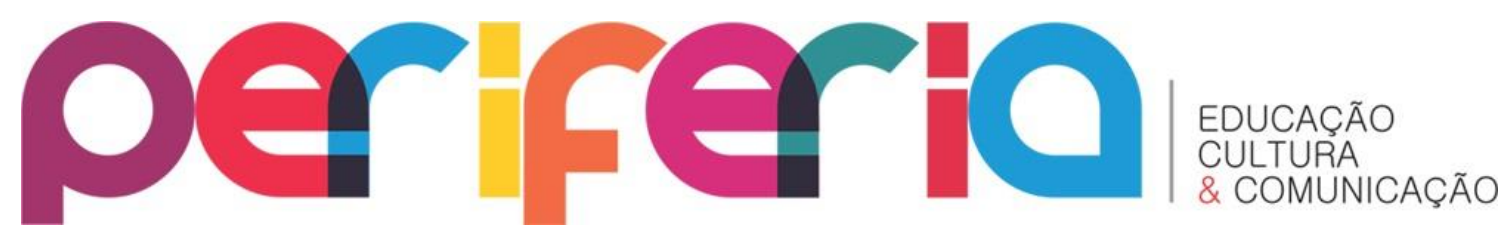

organizada e o projeto iniciado somente em maio de 2016. A expectativa é que o material estivesse pronto em agosto do mesmo ano, mas, pela complexidade do material, as primeiras aulas ficaram prontas apenas em setembro em 2016.

A partir das primeiras iniciativas, a coordenação da equipe verificou a necessidade de agregar ao grupo um estagiário que tivesse conhecimentos específicos a respeito da LIBRAS, além do domínio da língua. A equipe foi formada e um estagiário com conhecimento em Libras foi contratado. Ele promoveu, durante dois meses, um grupo de estudos para conscientização sobre a Libras e surdez, composto pelos funcionários da unidade, os estagiários das ciências exatas, os intérpretes vinculados à Unidade Inclusiva e o estudante surdo.

Para aprofundar mais nesse ambiente, foi realizada a participação em um fórum promovido pelo Instituto de Educação de Surdos (INES). Nesse evento, foram apresentados trabalhos relacionados à construção do projeto e também uma visita à TV INES, onde são produzidos materiais audiovisuais parecidos com o objetivo do projeto. Essa visita técnica foi de iniciativa dos próprios funcionários da Unidade à Distância, sendo que um total de sete pessoas participaram da viagem, entre funcionários, estagiários e o próprio estudante surdo. No trecho abaixo, retirado da entrevista com o funcionário da unidade de ensino à distância, João Daniel, observamos a importância dessa visita na construção da nova metodologia:

O que a gente percebeu lá [na visita à TV INES] é que até existem metodologias mas existem várias formas de se fazer e cada lugar tem um jeito. E esse jeito é gerado a partir da particularidade da equipe que eles têm, porque o ideal, num caso desses, é que tenha surdos na equipe, no caso deles tem e dentro da TV INES tem várias maneiras de fazer o mesmo produto porque tem um surdo que ele prefere pegar uma câmera de computador, pegar o texto em português e aí ele sinaliza e aí ele manda aquilo para o colega dele revisar, ele manda para o intérprete, tem uns que preferem que 0 intérprete faça o texto e aí o surdo vai analisar o vídeo.Então, lá dentro da TV, tem vários surdos, vários ouvintes, vários 


\section{periferio}

intérpretes, eles têm formas diferentes de trabalhar o mesmo material, métodos diferentes, mas para gerar um mesmo vídeo no final, depende da equipe.

Através desse trecho, pode-se observar que esses locais de produção de conteúdo não diferem tanto em relação ao arsenal tecnológico, ou seja, eles possuem equipamentos parecidos e programas semelhantes, o diferencial, portanto, são os componentes da equipe. 0 grupo retratado neste artigo possui apenas um integrante com conhecimento em Libras, a realidade é diferente. Além disso, a percepção do ouvinte e a do surdo são completamente distintas. A peculiaridade desse projeto repercute em ser necessário gravar o audioguia, por exemplo, para auxiliar o editor de vídeo na hora da edição do conteúdo gravado. Assim como, também, não ter um surdo para revisar esse conteúdo produzido.

Após essa etapa, iniciou-se a construção do material. 0 primeiro desafio foi criar uma metodologia para a adaptação do conteúdo. A unidade possui vários modelos de aulas, mas nenhum acessível a surdos. 0 funcionário da unidade, João Eduardo, conta em qual problematização surgiu a ideia de criar o novo método:

Quando você tá fazendo um material que é pra ouvinte, você tem duas mídias funcionando simultaneamente, que é a visão e a audição. Então, se você olha para um figura, você continua ouvindo o que a pessoa fala. No caso do surdo não tem como, se ele olha pra figura, ele perde o que o professor está sinalizando, essa é uma das dificuldades, inclusive da gente achar, será que isso não já existe uma fórmula, um método pronto? E a gente viu que não existe, então a gente partiu para esse esquema de realmente produzir e gerar o método.

Diante dessa dificuldade de criar um material que conciliasse sinalização e escrita, a equipe, depois dos estudos, criou o modelo aula sinalizada, que é uma adaptação do método já existente, aula narrada, porém em versão de sinais, intercalando o vídeo com a tradução em Libras com o conteúdo e imagens referentes à matéria (SOUZA \& JÚNIOR, 2016). 


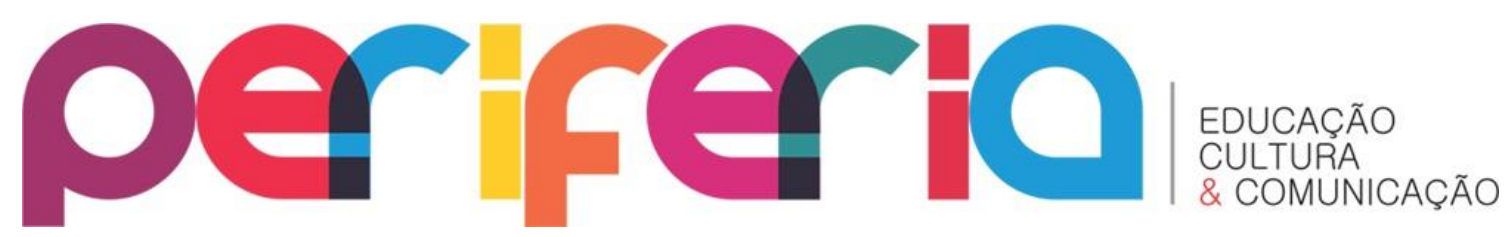

Para esse método acontecer, os estagiários da ciências exatas, junto aos professores da disciplina, montam um material em slide. Este passado para o estagiário com conhecimento em Libras que traduz o material para a língua de sinais. Essa tradução é revisada pelo coordenador da Unidade Inclusiva e, posteriormente, é montado uma glosa em português. Nesse trecho da entrevista, João Felipe, funcionário da unidade de ensino à distância, conta sobre a função do audioguia:

o audioguia eu gravo exatamente o que eu tenho que fazer para manter a sincronia com o slide, por exemplo, aparece aqui que tô sinalizando [aponta para o centro da tela], aí aparece o título aqui [aponta para a parte superior e central da tela] e eu aponto para o título [aponta para cima], ou eu tô sinalizando aí aparece, sei lá, estrutura, uma via, rodovias por exemplo, aí eu mostro aqui [aponta para o lado direito da tela] e aparece uma imagem de uma rodovia.

Nota-se, então, como foi sanado o problema de conciliação da escrita com a sinalização. É importante ressaltar que a construção e composição das frases em Libras são diferentes do português, os aspectos gramaticais se divergem. A ordem dos constituintes das sentenças, a distinção de gênero, a concordância, o aspecto e o tempo verbais e a intensidade são pontos diferentes na gramática das duas línguas. Portanto, o material do professor é em português, estruturado com suas palavras e sua forma de ensinar. A versão construída em Libras é uma adaptação feita pela equipe (estagiários das disciplinas, técnicos e intérpretes) para um melhor entendimento do surdo em relação ao material.

Um outro problema enfrentado foi a falta de sinais específicos do campo estudado nas ciências exatas. Vários termos técnicos não possuíam sinais e isso dificultava o trabalho. Pensou-se, a princípio, em criar os sinais que ainda não existiam, mas após algumas tentativas, foi avaliado que esse processo é demorado, pois é necessário um trabalho envolvendo ao menos um surdo no processo criativo e, além disso, é necessário o reconhecimento desse sinal por parte da comunidade surda (KUHN, 2014) já que o sinal criado fora 


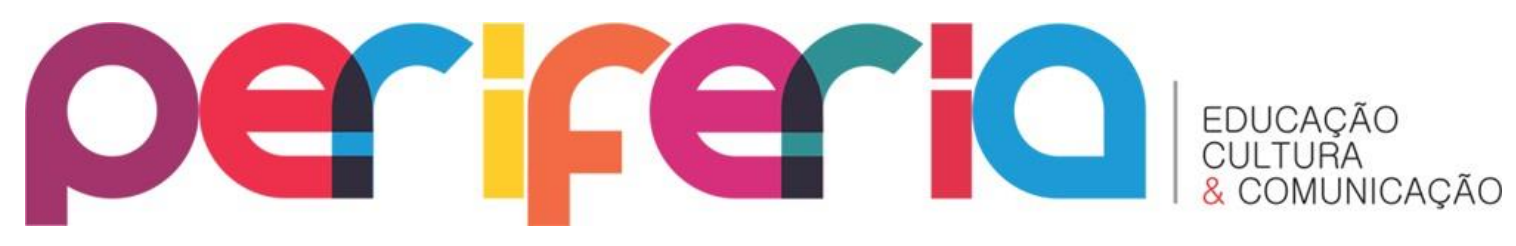

desta comunidade poderia ser rejeitado, o que implicaria em sua inutilização.

Como o cronograma da produção do projeto era bem apertado, decidiuse abordar outro método. Portanto, a metodologia foi adaptada para que os estagiários das ciências exatas organizassem previamente um roteiro e 0 enviassem, em seguida, para o surdo e intérpretes. Estes se encarregaram de estudá-lo e de listar os conceitos que não possuiam um sinal em Libras. Posteriormente, os monitores escreviam a definição direta e clara das palavras dessa lista, explicitando seu significado para o aluno surdo.

Com todos esses materiais prontos, a equipe de gravação iniciou seu trabalho no estúdio. Essa fase também precisou passar por processos de adaptação, pois, segundo pesquisas exploratórias, o quadro com os intérpretes costuma ser muito pequeno e não permite a visualização dos detalhes.

Para a confecção desse material, foram consideradas as especificidades gramaticais da Libras, portanto, as aulas foram organizadas da seguinte forma: foi destinado $1 / 4$ da tela para o quadro de interpretação, pois os funcionários perceberam que o tamanho utilizado pela maioria dos canais de TV (1/8) não era suficiente para o surdo absorver o conteúdo transmitido. 0 enquadramento também precisou ser alterado. Para possibilitar o campo visual-espacial (QUADROS; KARNOPP, 2004), a distância definida do intérprete para a tela foi delimitada ao espaço de um palmo acima da cabeça e, nas laterais, a distância foi estabelecida pelos cotovelos abertos, formando dois triângulos com as mãos entrelaçadas no peitoral.

Até o momento da presente pesquisa, apenas duas aulas haviam sido concluídas e, por isso, ainda não é possível estabelecer o tempo médio de produção do material. O material produzido fica disponível no ambiente virtual de aprendizagem da instituição estudada.

0 projeto é pioneiro na área específica de atuação nas ciências exatas no Brasil e a expectativa é que se utilize essa metodologia para a produção de mais materiais acessíveis para os estudantes surdos atuais e futuros da instituição. 


\section{periferio}

\section{CONCLUSÃO}

A partir deste trabalho, foi possível observar uma experiência relacionada ao desafio que é promover a acessibilidade dentro do ensino superior. É comum a ausência de apoio por parte da instituição e alguns surdos abandonam o curso por não conseguirem se comunicar. Portanto, práticas como essas são necessárias para promover a inclusão e trazer uma nova realidade para o ensino superior. Desde a criação das leis, declarações e decretos, o movimento tem ganhado força.

A construção da aula sinalizada foi um grande desafio para a metodologia de ensino para surdos, pois, como ficou evidenciado, trata-se de um método que, apesar de eficaz, mobiliza vários agentes. 0 desenvolvimento desses materiais, além de proporcionar ao surdo uma real aprendizagem do conteúdo, proporciona também uma maior proximidade e integração ao cotidiano universitário.

Os conceitos de redistribuição e reconhecimento, abordados por Nancy Fraser e Axel Honneth (2003), que apelam dimensões distintas no processo de inclusão social, permitem repensar o problema aqui colocado para além da mera oferta de acesso material dos surdos ao ensino superior. Os temas da igualdade e acessibilidade, ainda que discutidos e defendidos de maneira veemente na sociedade, são de difícil efetivação. Os fatos aqui relatados, em relação à admissão do português em materiais didáticos para surdos e de emissões televisivas em que o intérprete de Libras se encontra tão reduzido na tela que inviabiliza a comunicação, são exemplos desse ponto.

Notou-se, também, que a pesquisa constituiu um mapeamento da rede voltada para a construção de TICs direcionadas para a educação inclusiva na instituição de ensino superior da zona da mata mineira. Essa rede pode ser classificada como fechada devido à repetição de estrelas e integrantes. Pode também ser vista como aberta, pois as mesmas pessoas desenvolvem os papéis semelhantes na rede. É ainda limitada, por haver pouca diversidade de 


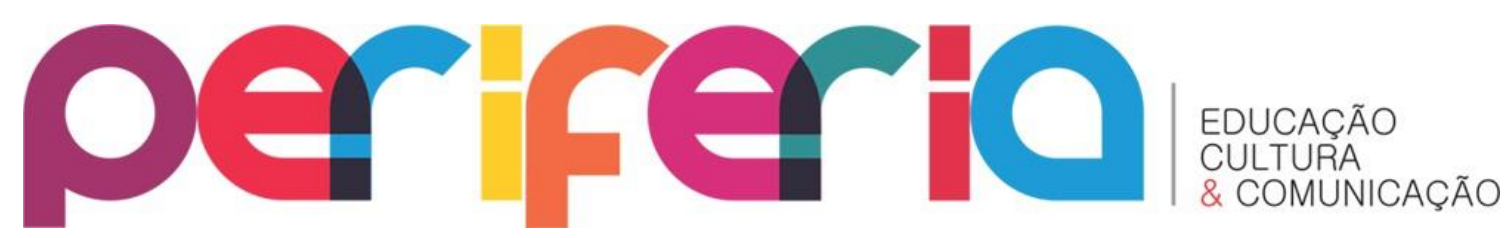

membros e, igualmente, interdisciplinar, pois os profissionais possuem especialização em diferentes áreas do conhecimento.

O material ainda está em fase de produção, apenas algumas aulas estão disponíveis, porém, segundo relatos do estudante surdo, a aula sinalizada foi um grande diferencial para estudar e compreender os conteúdos abordados no curso.

Assim, a criação de conteúdos didáticos acessíveis não se restringe a um aspecto meramente material de acesso à educação superior, mas, especialmente, esses conteúdos são capazes de promover processos de reconhecimento da diferença surda no âmbito da sociedade e do ensino superior brasileiros.

\section{REFERÊNCIAS}

ALMEIDA, Júnior Fonseca; ALMEIDA, Maria Elizabeth. Avaliação em meio digital: novos espaços e outros tempos. In: ALMEIDA, F. J. Avaliação educacional em debate: experiências no Brasil e na França. São Paulo: Cortez; Editora da PUCSP - Educ, 2005.

BARNES, John Arundel. Class and Committees in a Norwegian Island Parish. Human Relations, $\mathrm{n}^{\circ}$ 7, 1964.

- Redes sociais e processo político. In: FELDMAN-BIANCO, Bela (Org.). Antropologia das Sociedades Contemporâneas. São Paulo: Global, 1987.

BRASIL. Lei $\mathrm{n}^{\circ} 9.394$ de 20 de dezembro de 1996, que estabelece as diretrizes e bases da educação nacional. Publicada no Diário Oficial da União em 20 de dezembro de 1996.

. Lei $\mathrm{n}^{\circ} 10.436$ de 24 de abril de 2002, que dispõe sobre a Língua Brasileira de Sinais - LIBRAS, e dá outras providências. Publicada no Diário Oficial da União em 24 de abril de 2002.

- Declaração de Salamanca e Linha de Ação sobre Necessidades Educativas Especiais. Brasília: Coordenadoria Nacional para Integração da Pessoa Portadora de Deficiência, 1994.

- Decreto $n^{\circ} 5.626$ de 22 de dezembro de 2005, que regulamenta a Lei $\mathrm{n}^{\circ} 10.436$ de 24 de abril de 2002, que dispõe sobre a Língua Brasileira de Sinais - LIBRAS, e o art. 18 da Lei 10.098, de 19 de dezembro de 2000. 


\section{periferio}

Publicada no Diário Oficial da União em 22 de dezembro de 2005.

- Ministério da Educação. Secretaria de Educação Especial. Política Nacional de Educação Especial na perspectiva da Educação Inclusiva. Brasília: MEC/INEP, 2012.

FERREIRA BRITO, Lucinda. Por uma gramática de línguas de sinais. Rio de Janeiro: Tempo Brasileiro, 1995.

FRASER, Nancy. Da redistribuição ao reconhecimento? Dilemas da justiça numa era "pós-socialista". Cadernos de Campo, n. 14/15, p. 231-239, 2006.

FRASER, Nancy; HONNETH, Axel. Redistribution or recognition? A politicalphilosophical exchange. New York: Verso, 2003.

GARRISON, Randy.; VAUGHAN, Norman. Blended Learning in Higher Education. São Francisco: Jossey-Bass, 2008.

GEDIEL, Ana Luísa Borba; SOARES, Charley Pereira; OLIVEIRA, Cristiane Lopes Rocha. $O$ ambiente virtual como aliado no processo de ensino e aprendizagem da Libras. Revista (Con) Textos Linguísticos, v. 10, n. 16. Vitória: UFES, 2016

GESSER, Audrei. LIBRAS? Que língua é essa? Crenças e preconceitos em torno da língua de sinais e da realidade surda. São Paulo: Parábola, 2009.

HONNETH, Axel. Luta por reconhecimento: a gramática moral dos conflitos sociais. Ed. 34, 2003, p. 07-19

KUHN, Talícia do Carmo Galan. Processo Criação de Termos Técnicos em Libras para Engenharia de Produção. Ponta Grossa: 2014, 92p. Tese (Mestrado em Ensino de Ciência e Tecnologia). Programa de Pós-Graduação em Ensino de Ciência e Tecnologia, Universidade Tecnológica Federal do Paraná.

MARTINELLI, Marilu. Conversando sobre educação em valores humanos. 3 ed. São Paulo: Peirópolis, 1999.

MOROSOV, Katia. Tecnologias da Informação e Comunicação e formação de professor: sobre rede e escolas. Educ. Soc., Campinas, vol. 29, n. 104 - Especial, p. 747-768, out. 2008.

QUADROS, Ronice Müller de; KARNOPP Lodenir. Língua de sinais brasileira: estudos linguísticos. Coleção de Cadernos CED, n.13. Porto Alegre: ARTMED, 2004, p. 221.

QUARESMA, Valdete. Boni. Aprendendo a entrevistar: como fazer entrevistas em Ciências Sociais. Revista Eletrônica dos Pós-Graduandos em Sociologia Política da UFSC, Vol. 2 n 1 (3), janeiro-julho/2005, p. 68-80. 


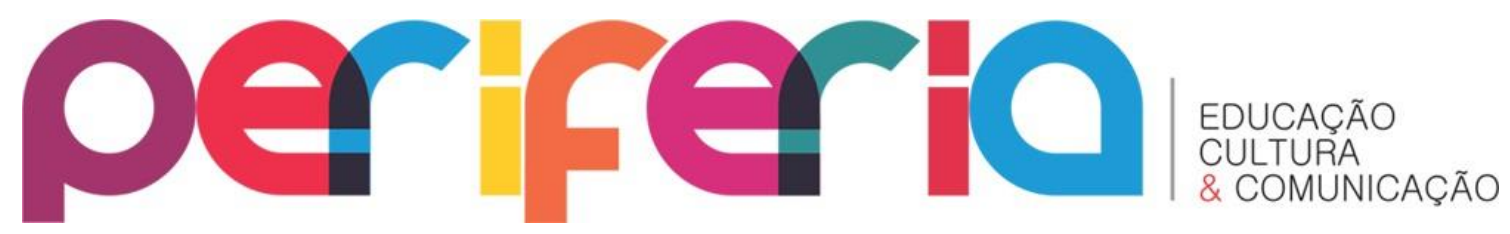

SCHLÜNZEN JÚNIOR., Klaus; SCHLÜNZEN, Elisa Tomoe Moriya; SANTOS, Danielle Aparecida Nascimento dos; MALHEIRO, Cicera Aparecida. Lima. Tecnologia assistiva e educação híbrida: possibilidades de inclusão. Benjamin Constant, ano 22, edição especial, setembro 2016, p.40-54.

STOKOE, William C. Sign Language Structure. Silver Spring: Linstok Press., 1960/1978. Revisto em 1978, Silver Spring, M.D., Linstok Press.

SOUZA, André Luís Santos de; JÚNIOR, José Timoteo. O uso de tecnologias (TIC) na produção de material didático bilíngue libras/português na Universidade Federal de Viçosa. Revista Fórum (INES), n. 33, p. 92-109, 2016.

TRIVIÑOS, Augusto Nibaldo Silva. Introdução à pesquisa em ciências sociais: $a$ pesquisa qualitativa em educação. São Paulo: Atlas, 1987. 